\title{
Références bibliographiques du dossier « Diriger un établissement scolaire »
}

\section{Dominique Pommellet}

\section{(2) OpenEdition \\ 1 Journals}

Édition électronique

URL : http://journals.openedition.org/ries/4213

DOI : 10.4000/ries.4213

ISSN : 2261-4265

Éditeur

Centre international d'études pédagogiques

\section{Édition imprimée}

Date de publication : 1 décembre 1994

Pagination : 139-141

ISSN : 1254-4590

\section{Référence électronique}

Dominique Pommellet, "Références bibliographiques du dossier « Diriger un établissement scolaire » », Revue internationale d'éducation de Sèvres [En ligne], 04 | 1994, mis en ligne le 17 avril 2015, consulté le 08 janvier 2020. URL : http://journals.openedition.org/ries/4213 ; DOI : 10.4000/ries.4213

Ce document a été généré automatiquement le 8 janvier 2020.

(c) Tous droits réservés 


\title{
Références bibliographiques du dossier « Diriger un établissement scolaire »
}

\author{
Dominique Pommellet
}

1 Cette courte bibliographie signale des références récentes (1990-1994). Les documents cités comportent eux-mêmes de nombreuses données complémentaires. Ils sont disponibles aux centres de documentation du CIEP et du Centre Condorcet qui a aimablement collaboré à ce travail.

2 BALLION Robert, Le lycée, une cité à construire. Paris, Hachette Éducation, 1993, 238 p. S'appuyant sur une enquête menée sur un échantillon de vingt-cinq établissements, l'auteur met à jour l'éventail des stratégies d'action conduites ici et là par les différents acteurs pour relever le défi du changement. On y découvre le lycée de demain: un établissement efficace voire un cadre de vie.

3 BAROSO Joao, SJORSLEV Sten, Les structures de l'administration et de l'évaluation des écoles primaires et secondaires dans les douze États membres de la Communauté européenne. Bruxelles, Eurydice, 1991, 173 p.

Approche comparée du fonctionnement des structures internes des établissements (conseils scolaires, conseils de coordination et d'orientation) ainsi que des compétences des chefs d'établissement dans le cadre de la décentralisation, de l'autonomie, de la gestion participative et des pratiques d'évaluation interne et externe.

DELAIRE Guy, Le chef d'établissement, techniques et pratiques du management. Paris, Berger-Levrault, 1993, $356 \mathrm{p}$.

La présentation des problèmes concrets et quotidiens rencontrés par le chef d'établissement dans l'exercice de ses fonctions, en France, est accompagnée d'une réflexion sur les instruments d'action, sur l'auto-évaluation et l'évaluation des établissements.

5 HOPES Clive (sous la direction de), Le chef d'établissement et l'amélioration du fonctionnement. Paris, Economica (OCDE-ISIP), 1988, 418 p. Études de cas de dix pays de l'OCDE. 
6 LANGLOIS Donald E., MCADAMS Richard P., Performance appraisal of school management : evaluating the administrative team. Lancaster (EU), Technomic, 1992, $166 \mathrm{p}$.

À propos de l'évaluation des équipes de direction aux États-Unis.

7 OBIN Jean-Pierre, La crise de l'organisation scolaire. Paris, Hachette Éducation, 1993, $351 \mathrm{p}$.

Comment évoluer de la centralisation bureaucratique au pilotage par objectifs et par projets pour responsabiliser et impliquer dans le changement les acteurs de l'institution scolaire.

PICQUENOT Alain, GUILLAUME François-Régis, KOKOSOWSKI Alain, et al., Les personnels des établissements secondaires. Paris, Hachette Éducation, 1993, 126 p.

Les conséquences de l'autonomie sur la fonction de chef d'établissement dans les domaines suivants: l'animation pédagogique, l'éducation et la vie scolaire, l'orientation, l'insertion et l'accueil, la gestion des moyens et des ressources humaines, l'information et la communication.

9 ROLLIN France, Chef d'établissement : des métiers, une passion. Lyon, Chronique sociale, (coll. l'Essentiel), 1992, $186 \mathrm{p}$.

Analyse du métier de chef d'établissement, de son évolution, de ses spécificités dans l'enseignement privé catholique sous contrat, conduite par une responsable de formation dans le cadre d'une réflexion sur l'élaboration d'un référentiel du métier et de la formation.

10 THODY Angela, Moving to management : school governors in the 1990s. Londres, David Fulton éd., 1992, 175 p.

Chef d'établissement, responsable de formation à l'université de Leicester, l'auteur présente l'évolution de la fonction d'administration de l'établissement scolaire en Grande-Bretagne.

11 On peut consulter également avec profit sur ce sujet les revues françaises et étrangères suivantes :

12 Administration et éducation

$\mathrm{n}^{\circ} 45,1990$, « Les cadres de l'Éducation ».

$\mathrm{n}^{\circ} 46,1990$, «Qui dirige l'établissement? »

$\mathrm{n}^{\circ} 57,1993$, « Le pilotage de l'établissement scolaire ».

$\mathrm{n}^{\circ} 59,1993$, « Piloter le système éducatif », Actes du XV colloque national.

13 Educational administration quaterly, en particulier :

vol. 28, n 1, février 1992, n², mai 1992, n³, août 1992.

vol. $29, \mathrm{n}^{\circ} 1$ février 1993.

Éducation et formations

$n^{\circ} 35$, juil. 1993, « Les chefs d'établissement et l'autonomie ».

Éducation et management, en particulier :

$n^{\circ} 7$, juin 1991, « Les ressources humaines ».

$\mathrm{n}^{\circ}$ 8, nov. 1991, « Les chefs d'établissement en Europe ».

$\mathrm{n}^{\circ} 10$, nov. 1992, «Les nouveaux responsables ».

$\mathrm{n}^{\circ} 12$, oct. 1993, «L'équipe de direction ».

$n^{\circ} 13$, avr. 1994, « Manager en Europe ». 
Educational management and administration

vol. 20, n 3, juil. 1992.

17

\section{Journal of research and development in education}

vol. 26, $\mathrm{n}^{\circ} 1,1992$.

18 La Lettre européenne de l'éducation, en particulier :

$\mathrm{n}^{\circ}$ 8, mars-avr. 1992, «Le chef d'établissement en Europe ».

19 Recherche et formation INRP, en particulier :

$\mathrm{n}^{\circ} 14$, oct. 1993, sur « la formation des chefs d'établissement ».

20 Savoir, éducation, formation, en particulier :

n 4 4, oct.-déc. 1991, sur « La responsabilité des chefs d'établissement ».

$\mathrm{n}^{\circ}$ 2, avr.juin 1992, «Personnels de direction, réflexions sur l'établissement; vers un référentiel de métier ».

$\mathrm{n}^{\circ}$ 1, janv.-mars 1993, «L'évolution actuelle des méthodes de mobilisation et d'encadrement des enseignants ».

\section{AUTEUR}

DOMINIQUE POMMELLET

CIEP 